\title{
Apoptosis in B-CLL: The relationship between higher ex vivo spontaneous apoptosis before treatment in III-IV Rai stage patients and poor outcome
}

\author{
MALGORZATA SIEKLUCKA ${ }^{1,2}$, PIOTR POZAROWSKI ${ }^{1}$, AGNIESZKA BOJARSKA-JUNAK ${ }^{1}$, \\ IWONA HUS ${ }^{2}$, ANNA DMOSZYNSKA ${ }^{2}$ and JACEK ROLINSKI ${ }^{1}$ \\ Departments of ${ }^{1}$ Clinical Immunology, ${ }^{2}$ Haematooncology and Bone \\ Marrow Transplantation, Medical University of Lublin, Poland
}

Received November 12, 2007; Accepted February 18, 2008

\begin{abstract}
B-cell chronic lymphocytic leukaemia (B-CLL) has been described as the progressive accumulation of matureappearing B cells in peripheral blood and bone marrow, resulting from failed apoptosis rather than from alterations in cell cycle regulation. Recent investigations suggest that high WBC and lymphocyte counts result not only from defects in apoptosis, but also from cell proliferation. In this study, we aimed to examine the process of apoptosis in B-CLL patients before and during anti-cancer therapy, to answer the question of whether this parameter would presage the response to treatment and the clinical course of the disease. We found that ex vivo spontaneous apoptosis was higher in advanced-stage (III-IV acc. Rai) than in early-stage (I-II acc. Rai) patients. In I-II Rai stage patients the percentage of ex vivo apoptotic cells after chemotherapy was higher than that of apoptotic cells prior to treatment, whereas in III-IV Rai stage patients the percentage of ex vivo apoptotic cells after chemotherapy was lower than that of apoptotic cells before the anti-cancer therapy. The results of our study, in the context of the cited literature, suggest a relationship between higher ex vivo spontaneous apoptosis before treatment in advanced-stage patients with a higher proliferation of leukaemic cells and poor outcome.
\end{abstract}

\section{Introduction}

Apoptosis, a form of programmed cell death, plays a major role in the regulation of tissue homeostasis. An imbalance

Correspondence to: Dr Malgorzata Sieklucka, Department of Clinical Immunology, Medical University of Lublin, Jaczewskiego 8, 20-954 Lublin, Poland

E-mail:magsie@interia.pl

Key words: B-cell chronic lymphocytic leukaemia, apoptosis, ex vivo, mitochondrial membrane potential between cell death and proliferation may cause premature death or uncontrolled cell expansion. Therefore, failure in the apoptotic pathways can contribute to various diseases, including malignancies, such as leukaemia (1). Exploring this phenomenon is a matter of great importance for improving therapies or creating new treatments for many diseases.

B-cell chronic lymphocytic leukaemia (B-CLL) represents the most common form of leukaemia in adults of Western countries, which has been described as the progressive accumulation of mature-appearing B lymphocytes in the peripheral blood and bone marrow. It appears to be the result of failed apoptosis rather than of alterations in cell cycle regulation, as most B-CLL cells are arrested in $G_{0} / G_{1}(2-5)$. Moreover, while normal naive $\mathrm{B}$ cells have average half-lives of 5-7 days, the B-CLL cell half-lives last many months (6). In contrast, B-CLL cells rapidly enter spontaneous apoptosis in vitro $(7,8)$. However, the role of apoptosis in the mechanisms of disease progression remains unclear, and it is also possible that the apoptotic explanation is too simplistic. The latest literature suggests that apart from the long-lived peripheral blood cells with deregulated apoptosis pathways, the population of B-CLL cells may also comprise proliferating cells originated in the bone marrow, lymph nodes or spleen $(9,10)$. This may partially explain B-CLL heterogeneity.

It is likely that measuring the number of apoptotic cells in the peripheral blood before and after treatment may be a useful tool for studying the biology and assessing the susceptibility of leukaemic cells to agents inducing apoptosis. It is crucial to find a method that evaluates the very early stages of apoptosis ex vivo, when apoptotic cells are still present in the peripheral blood and before they are eliminated from circulation by phagocytes.

The clinical course of B-CLL patients can be extremely variable. This fact emphasises the role of prognostic factors, essential for developing risk-adapted therapeutic strategies in B-CLL. The latest valuable prognostic factors, found to predict the clinical course of the disease, included the status of somatic mutations in the Ig heavy-chain variable region (Ig VH) genes and $\zeta$-chain associated protein-70 (ZAP-70) or CD38 expression (11-13), the first being inaccessible for 
standard clinical laboratory testing, the latter two, as yet not standardised. However, the results of recent studies on ZAP70 expression in B-CLL are promising $(14,15)$. Nevertheless, the recognition of an easy-to-perform screening factor, enabling the division of B-CLL patients into good and poor prognosis subgroups, would be of great value. Since recent investigations suggest that high WBC and lymphocyte counts result not only from defects in programmed cell death leading to the accumulation of leukaemic cells, but also from their proliferation (16), we aimed to examine the process of apoptosis in untreated B-CLL patients, as well as in patients undergoing treatment, to ascertain if this parameter would presage the response to treatment and the clinical course of the disease.

\section{Materials and methods}

Patients. Between October 2001 and July 2007, peripheral blood (PB) was obtained from 96 previously untreated B-CLL patients (median age, 62.0 years; 63 male, 33 female) and 22 healthy individuals (median age, 55.0 years; 7 male, 15 female). Patients were diagnosed with B-CLL on the basis of a clinical examination, and morphological and immunological criteria. The clinical stage of B-CLL patients was defined at the time of diagnosis according to the Rai classification as follows: stage 0,11 patients; stage I, 24 patients; stage II, 39 patients; stage III, 7 patients and stage IV, 15 patients. The patient characteristics are shown in Table I. Of this group, 51 patients required therapy and received either purine analogues (43 patients) or alemtuzumab ( 8 patients). The local ethics committee approved this study, and informed consent was signed by all of the patients.

Cell isolation. Mononuclear cells were isolated from heparinised PB samples by density-gradient centrifugation on Gradisol-L (Aqua Medica, Poland). Interphase cells were washed twice in phosphate-buffered saline (PBS) and then re-suspended at $0.5-1 \times 10^{6}$ cells.

Flow cytometry. An analysis of apoptosis within the mononuclear cell population was performed using a BectonDickinson FacsCalibur flow cytometer (Becton-Dickinson, USA), equipped with a 488-nm argon laser. The analysis, using CellQuest software, was based on gating a subpopulation of lymphoid cells by forward (FSC) versus side scatter (SSC), excluding debris.

Cell-surface antigen expression. Mononuclear cells were stained with anti-CD3FITC/anti-CD19PE (Caltag Laboratories, USA), anti-CD19PE (Caltag Laboratories), anti-CD5 CyChrome (Caltag Laboratories), anti-CD23FITC (Dako, Denmark), anti-CD38 FITC (BD PharMingen, USA) or matched isotypic control as recommended by the manufacturer. The samples were then washed with PBS and analysed by flow cytometry.

ZAP-70 expression. ZAP-70 expression was performed using a Zenon $^{\mathrm{TM}}$ AlexaFluor ${ }^{\circledR} 488$ Mouse $\operatorname{IgG}_{2 \mathrm{a}}$ labelling kit (Molecular Probes, USA), as described previously by us $(14,16)$. In brief, mononuclear cells stained with anti-CD19PE and anti-CD5CyChrome MoAbs were fixed and permeabilised with the IntraPrep kit (Immunotech, France) according to the manufacturer's instructions. Thereafter, anti-ZAP-70 antibody (Upstate Biotechnology, USA) labelled by a Zenon ${ }^{\mathrm{TM}}$

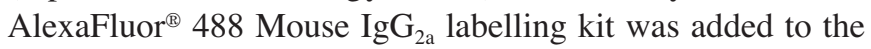
samples. The samples were incubated for $30 \mathrm{~min}$ at room temperature, washed with PBS and analysed by flow cytometry immediately. The cut-off point for ZAP-70 positivity in leukaemic cells was $\geq 20 \%$.

Apoptosis. The percentage of apoptotic cells in B-CLL patients was measured at the time of diagnosis, as well as 3, 24 and $48 \mathrm{~h}$ after the first dose of drug administration (during the initial cycle of therapy). The percentage of apoptotic cells in B-CLL patients at the time of diagnosis was compared to that of apoptotic cells in healthy control subjects. Three different methods were used to assess apoptosis (Fig. 1).

1) Chloromethyl-X-rosamine staining (Mito Tracker Red CMXRos, Molecular Probes, USA). CMXRos is a cationic lipophilic fluorochrome that does not accumulate in depolarised mitochondria and thus can be used to detect disruptions in the mitochondrial membrane potential $\left(\Delta \Psi_{\mathrm{m}}\right)$. CMXRos was used in combination with the monoclonal anti-glycophorin A/FITC-conjugated antibody (Dako) to label glycophorin A on the cell surface of erythrocytes. It was proved useful with erythrocyte-contaminated samples with erythrocytes displaying a low $\Delta \Psi_{\mathrm{m}}$, similar to apoptotic cells (17-20).

CMXRos was prepared as a stock solution in dimethylsolfoxide (DMSO) and stored at $-20^{\circ} \mathrm{C}$. Cells were resuspended in $0.5 \mathrm{ml}$ of complete culture medium with $0.2 \mu \mathrm{M}$ CMXRos working solution and incubated for $30 \mathrm{~min}$ at $37^{\circ} \mathrm{C}$. For the last $15 \mathrm{~min}$ of incubation, anti-glycophorin A (FITC) monoclonal antibody was added at the concentration recommended by the manufacturer. Cells were acquired and analysed by a flow cytometer immediately after the incubation period. Cells considered to be apoptotic displayed a decrease in the mitochondrial membrane potential in CMXRos staining and were glycophorin A-negative $\left(\Delta \Psi_{\mathrm{m}}^{\text {low }} / \mathrm{Gly}-\mathrm{A}^{-}\right)$.

2) Fluorescein-diacetate (FDA) staining (Sigma, Germany). FDA is taken up by vital cells, hydrolysed there by esterases, with free fluorescein being the product of this reaction. Necrotic cells are identified with propidium iodide (PI), which permeates into necrotic cells and cells in the necrotic phase of apoptosis (21).

FDA was prepared as a stock solution in acetone and stored at $-20^{\circ} \mathrm{C}$. Cells were incubated with $10 \mathrm{nM}$ FDA working solution for $5 \mathrm{~min}$ at room temperature. PI was then added (to the final concentration of $1 \mu \mathrm{g} / \mathrm{ml}$ ) and samples were analysed by a flow cytometer. Cells considered to be apoptotic were FDA and PI negative (FDA- $\left./ \mathrm{PI}^{-}\right)$.

3) Annexin V technique. This technique (TACS Annexin VFITC apoptosis detection kit, R\&D Systems, Germany) enables the investigation of plasma membrane alterations at two different steps: 1) phosphatidylserine (PS) redistribution from the inner plasma membrane leaflet to the outer leaflet can be detected by Annexin V (FITC-conjugated), binding to PS, while 2) the loss of plasma membrane integrity can be shown by PI $(21,22)$.

Cells were incubated with a TACS Annexin V-FITC apoptosis detection kit as recommended by the manufacturer and samples were analysed by a flow cytometer. Cells 


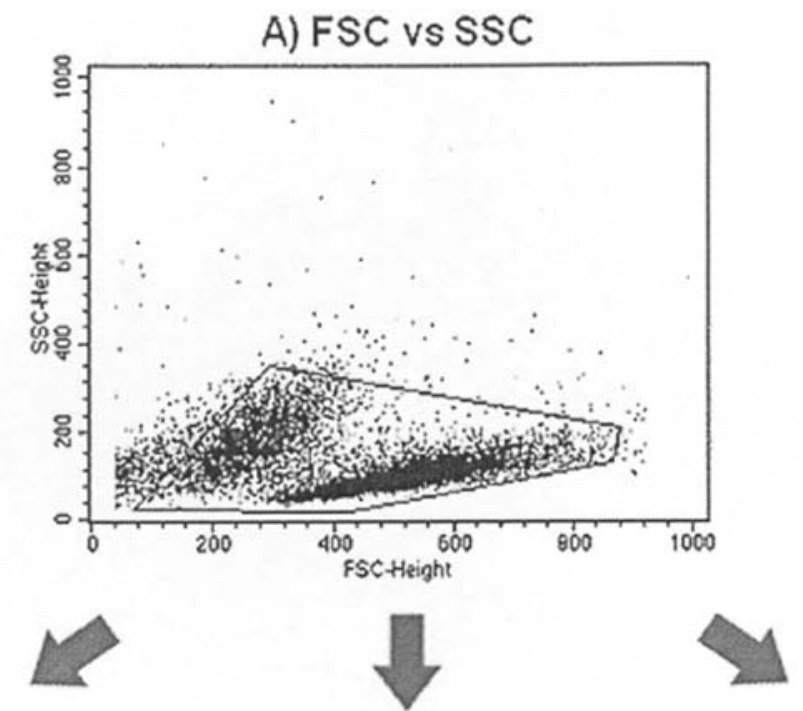

B) CMXRos

C) FDA

D) Annexin V

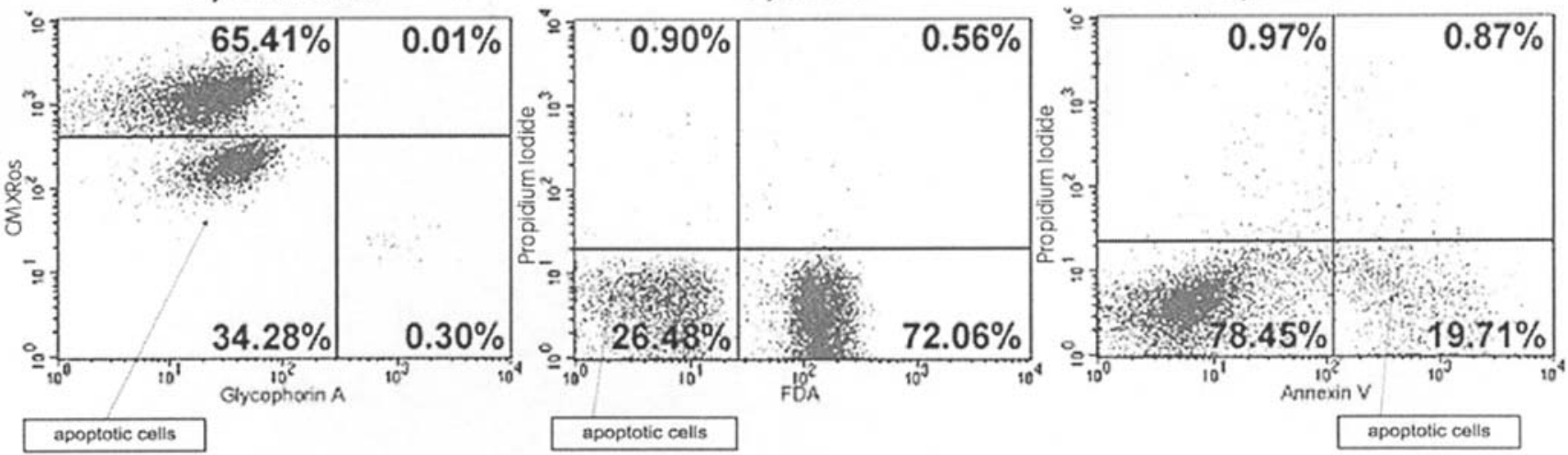

Figure 1. The flow cytometry dot plots show the analysis of the ex vivo percentage of apoptotic cells. The data are from a single B-CLL patient, P60. The analysis was based on gating a subpopulation of lymphoid cells by forward (FSC) versus side scatter (SSC) (A). The gated events were then analysed for CMXRos (B), FDA (C) and Annexin V (D) techniques. (B) CMXRos was used to detect disruptions in the mitochondrial membrane potential ( $\triangle \Psi_{\mathrm{m}}$ ), and the monoclonal anti-glycophorin A/FITC-conjugated antibody, to label glycophorin A on the cell surface of erythrocytes. Cells considered to be apoptotic displayed a decrease in the mitochondrial membrane potential in CMXRos staining and were glycophorin A-negative $\left(\Delta \Psi_{\mathrm{m}}{ }^{\text {low/Gly-A}} \mathrm{A}^{-}\right)$, shown in the lower left quadrant of the dot plot (34.28\%). (C) FDA was used to assess vital cells, in which free fluorescein was released. Necrotic cells were identified with propidium iodide (PI). Cells considered to be apoptotic were FDA- and PI-negative (FDA-PI-), shown in the lower left quadrant of the dot plot (26.48\%). (D) Annexin V (FITCconjugated) was used to evaluate phosphatidylserine (PS) redistribution to the outer plasma membrane leaflet, while the loss of plasma membrane integrity was demonstrated by PI. Cells considered to be apoptotic displayed PS expression and were PI negative (Ann- $\left.\mathrm{V}^{+} / \mathrm{PI}\right)$, shown in the lower right quadrant of the dot plot $(19.71 \%)$

considered to be apoptotic displayed PS expression and were PI negative (Ann- $\left.\mathrm{V}^{+} / \mathrm{PI}^{-}\right)$.

Cell culture. The mononuclear cells of B-CLL patients and healthy individuals were cultured in RPMI-1640 medium supplemented with $2 \mathrm{mM}$ L-glutamine, $\mathrm{NaHCO}_{3}, 100 \mathrm{U} / \mathrm{ml}$ penicillin, $100 \mu \mathrm{g} / \mathrm{ml}$ streptomycin and $10 \%$ heat-inactivated foetal calf serum at $37^{\circ} \mathrm{C}$ in a humidified atmosphere containing $5 \%$ carbon dioxide for $48 \mathrm{~h}$.

Statistical analysis. The Mann-Whitney U test was applied for the statistical comparison of the results. The Spearman rank test was used to assess the correlation between the variables. P-values $\leq 0.05$ were considered significant. The results are expressed as median, min.-max., 25-75\%, non-outlier range, outliers and extreme values or the mean value \pm standard deviation (SD). Statistica 5.0 PL and Microsoft Excel 2000 software were used for statistical procedures.

\section{Results}

Assessment of the percentage of apoptotic cells in previously untreated B-CLL patients and in healthy individuals (Fig. 2) CMXRos staining. We found that the ex vivo percentage of peripheral blood (PB) apoptotic $\left(\Delta \Psi_{\mathrm{m}}^{\text {low }} / \mathrm{Gly}-\mathrm{A}^{-}\right)$cells in untreated B-CLL patients (mean 3.7 $\pm 4.3 \%$ and median $2.5 \%$ ) was significantly lower $(\mathrm{p}<0.001)$ than that of $\Delta \Psi_{\mathrm{m}}^{\text {low }} / \mathrm{Gly}-\mathrm{A}^{-}$ apoptotic cells in healthy subjects (mean $7.3 \pm 4.9 \%$ and median $5.5 \%$ ).

FDA. The ex vivo percentage of $\mathrm{PB}$ apoptotic (FDA-/PI-) cells in untreated B-CLL patients (mean $1.8 \pm 1.4 \%$ and median $1.5 \%)$ was also significantly lower $(\mathrm{p}<0.001)$ than that of the FDA-/PI- apoptotic cells in healthy controls (mean $4.0 \pm 2.8 \%$, median $3.7 \%$ ).

Annexin $V$. Similarly, the ex vivo percentage of PB apoptotic $\left(\right.$ Ann- $\left.\mathrm{V}^{+} / \mathrm{PI}^{-}\right)$cells in untreated B-CLL patients (mean $1.5 \pm 1.3 \%$ and median $1.2 \%$ ) was significantly lower 
Table I. The characteristics of B-CLL patients.

\begin{tabular}{|c|c|c|c|}
\hline \multicolumn{2}{|c|}{ Patient characteristics } & \multicolumn{2}{|c|}{ Rai stage } \\
\hline & & 0 -II & III-IV \\
\hline No. of patients & & 46 & 19 \\
\hline Gender (F/M) & & $17 / 29$ & $3 / 16$ \\
\hline $\begin{array}{l}\text { Age } \\
\text { (years) }\end{array}$ & $\begin{array}{c}\text { Mean } \pm \text { SD } \\
\text { Median } \\
\text { (min.-max.) }\end{array}$ & $\begin{array}{c}61.2 \pm 10.2 \\
61.0 \\
(38.0-79.0)\end{array}$ & $\begin{array}{c}63.8 \pm 9.7 \\
64.0 \\
(48.0-78.0)\end{array}$ \\
\hline $\begin{array}{l}\text { WBC } \\
\left(1 \times 10^{9} / 1\right)\end{array}$ & $\begin{array}{c}\text { Mean } \pm \text { SD } \\
\text { Median } \\
\text { (min.-max.) }\end{array}$ & $\begin{array}{c}56.7 \pm 45.9 \\
48.8 \\
(9.0-213.0)\end{array}$ & $\begin{array}{c}117.0 \pm 107.1 \\
83.0 \\
(18.2-360.0)\end{array}$ \\
\hline $\begin{array}{l}\text { Lymphocyte count } \\
\qquad\left(1 \times 10^{9} / 1\right)\end{array}$ & $\begin{array}{c}\text { Mean } \pm \text { SD } \\
\text { Median } \\
\text { (min.-max.) }\end{array}$ & $\begin{array}{c}50.3 \pm 40.5 \\
45.4 \\
(6.4-193.8)\end{array}$ & $\begin{array}{c}90.9 \pm 76.4 \\
76.8 \\
(10.2-252.0)\end{array}$ \\
\hline $\begin{array}{l}\mathrm{Hb} \\
\qquad(\mathrm{g} / \mathrm{dl})\end{array}$ & $\begin{array}{c}\text { Mean } \pm \text { SD } \\
\text { Median } \\
\text { (min.-max.) }\end{array}$ & $\begin{array}{c}13.4 \pm 1.3 \\
13.3 \\
(11.1-16.7)\end{array}$ & $\begin{array}{c}11.5 \pm 2.2 \\
11.1 \\
(7.6-15.1)\end{array}$ \\
\hline $\begin{array}{l}\text { Plt } \\
\qquad\left(1 \times 10^{9} / 1\right)\end{array}$ & $\begin{array}{c}\text { Mean } \pm \text { SD } \\
\text { Median } \\
\text { (min.-max.) }\end{array}$ & $\begin{array}{c}191.4 \pm 76.9 \\
180.0 \\
(102.0-543.0)\end{array}$ & $\begin{array}{c}97.9 \pm 52.7 \\
93.0 \\
(26.0-191.0)\end{array}$ \\
\hline $\begin{array}{l}\mathrm{LDH} \\
(\mathrm{IU} / \mathrm{l})\end{array}$ & $\begin{array}{c}\text { Mean } \pm \text { SD } \\
\text { Median } \\
\text { (min.-max.) }\end{array}$ & $\begin{array}{c}356.3 \pm 167.0 \\
322.0 \\
(134.0-818.0)\end{array}$ & $\begin{array}{c}312.4 \pm 110.3 \\
315.5 \\
(157.0-522.0)\end{array}$ \\
\hline $\begin{array}{l}\beta_{2} \text {-microglobulin } \\
(\mathrm{mg} / \mathrm{l})\end{array}$ & $\begin{array}{c}\text { Mean } \pm \text { SD } \\
\text { Median } \\
\text { (min.-max.) }\end{array}$ & $\begin{array}{c}4.1 \pm 4.4 \\
2.6 \\
(0.4-18.2)\end{array}$ & $\begin{array}{c}5.0 \pm 2.6 \\
4.0 \\
(1.9-10.5)\end{array}$ \\
\hline
\end{tabular}

$(\mathrm{p}<0.001)$ than that of the Ann- $\mathrm{V}^{+} / \mathrm{PI}^{-}$apoptotic cells in healthy individuals (mean $3.9 \pm 1.4 \%$ and median $3.8 \%$ ).

Relationship between the percentage of apoptotic cells and clinical parameters of $B-C L L$. The results of our research were analysed in association with the principal prognostic factors identified in B-CLL. There were inverse correlations between the ex vivo percentage of $\Delta \Psi_{\mathrm{m}}^{\text {low }} / \mathrm{Gly}-\mathrm{A}^{-}$apoptotic cells and leukocytosis and lymphocytosis in untreated B-CLL patients $(\mathrm{R}=-0.3, \mathrm{p}<0.05)$. However, we did not observe significant correlations between the ex vivo percentage of apoptotic cells and such prognostic factors as the lactate dehydrogenase $(\mathrm{LDH})$ or $\beta_{2}$-microglobulin levels, as well as CD38 or ZAP-70 expression.

Relationship between the percentage of apoptotic cells and the Rai stage. Ex vivo apoptosis was compared between patients in early ( 0 , I and II) versus late (III and IV) stages of B-CLL.

CMXRos. A direct correlation was found between the percentage of PB apoptotic $\left(\Delta \Psi_{\mathrm{m}}^{\text {low }} / \mathrm{Gly}-\mathrm{A}^{-}\right)$cells and the Rai stage $(\mathrm{R}=0.64, \mathrm{p}<0.05)$ in untreated $\mathrm{B}-\mathrm{CLL}$ patients. When compared, the advanced-stage (III-IV acc. Rai) patients showed a significantly higher $(\mathrm{p}<0.01)$ percentage of ex vivo

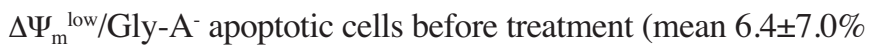
and median $4.1 \%$ ) than the early-stage (0-II acc. Rai) patients (mean 2.8 $\pm 2.5 \%$ and median 2.2\%), (Fig. 2).

$F D A$. A direct correlation was also found between the percentage of $\mathrm{PB}$ apoptotic (FDA-/PI-) cells and the Rai stage $(\mathrm{R}=0.5, \mathrm{p}<0.01)$ in untreated B-CLL patients. The patients with advanced disease (III-IV acc. Rai) showed a significantly higher $(\mathrm{p}<0.01)$ percentage of ex vivo FDA-/PI- apoptotic cells before treatment (mean $2.5 \pm 1.1 \%$ and median $2.5 \%$ ) than the early-stage (0-II acc. Rai) patients (mean $1.5 \pm 1.5 \%$ and median 1.0\%), (Fig. 2).

Annexin $V$. The advanced-stage (III-IV acc. Rai) patients showed a higher percentage of ex vivo PB apoptotic (Ann$\mathrm{V}^{+} / \mathrm{PI}^{-}$) cells before treatment (mean $1.8 \pm 1.6 \%$ and median $1.4 \%)$ than the early-stage (0-II acc. Rai) patients (mean $1.4 \pm 1.2 \%$ and median $1.1 \%$, NS), (Fig. 2).

Differences between the percentage of apoptotic cells before and after purine analogue administration. In patients receiving purine analogues the percentage of apoptotic cells was evaluated before treatment, as well as 3 and $24 \mathrm{~h}$ after the first dose of drug administration (during the initial cycle of 
A

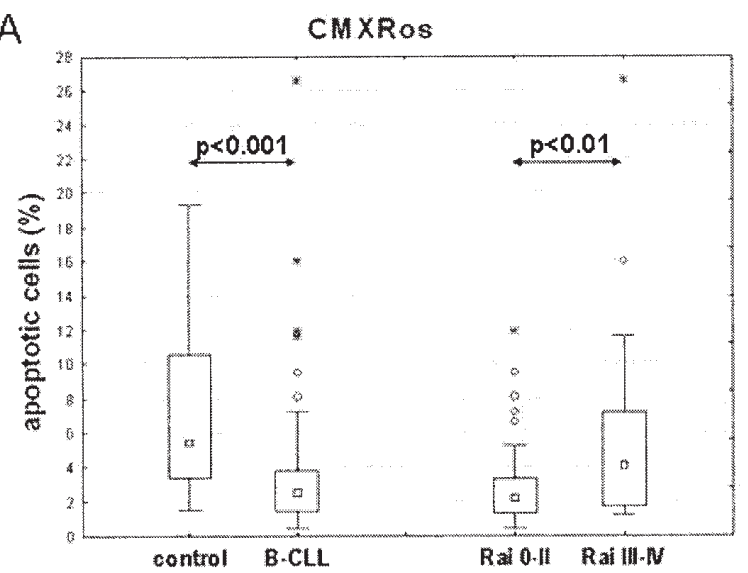

C

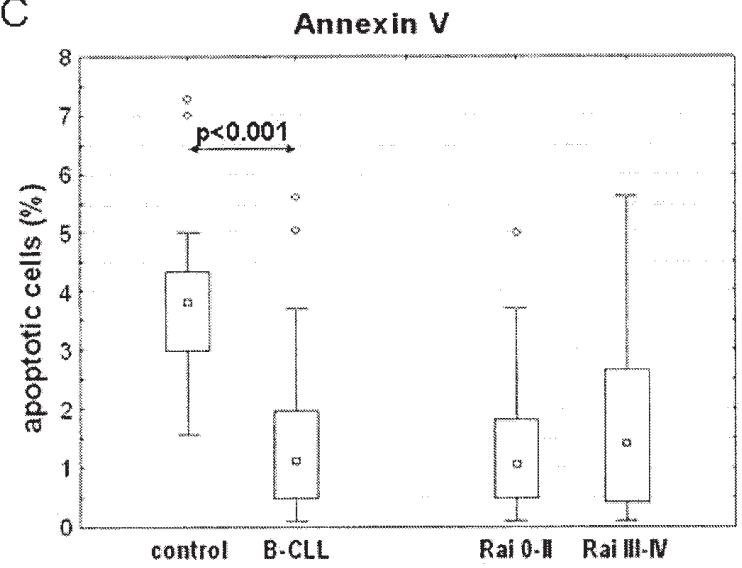

$\mathrm{B}$

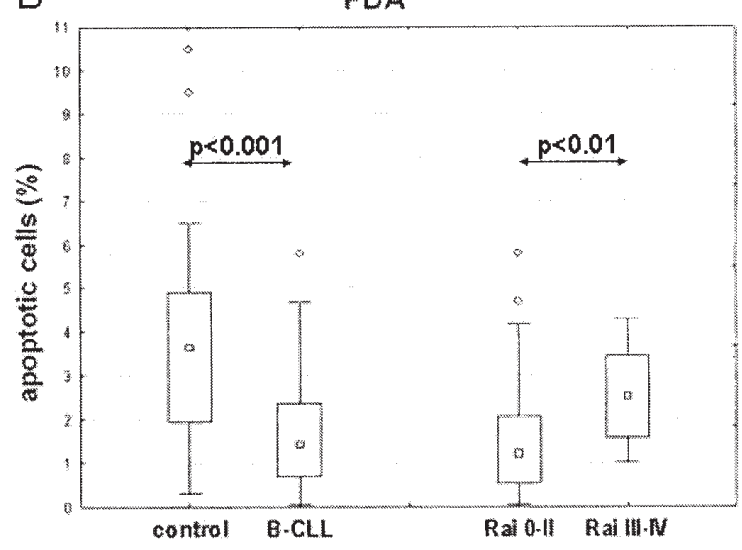

- Median

$\square 25 \%-75 \%$

I Non-outlier range

- Outliers

* Extreme values

Figure 2. The ex vivo percentage of apoptotic cells evaluated by CMXRos (A), FDA (B) and Annexin V (C) in healthy individuals (control) and previously untreated B-CLL patients (B-CLL). The latter group (CLL) was then divided into two subgroups according to Rai staging: 0-II and III-IV (the right side of each graph). We found that the ex vivo percentage of the peripheral blood apoptotic cells in untreated B-CLL patients was significantly lower (p<0.001) than that of apoptotic cells in healthy subjects. The patients with advanced disease (III-IV acc. Rai) showed a significantly higher (p<0.01) percentage of ex vivo apoptotic cells before treatment than the early-stage (0-II acc. Rai) patients.

therapy). In brief, we found that while the level of posttreatment apoptosis increased (compared to pre-treatment apoptosis) in 0-II Rai stage patients, it decreased in III-IV Rai stage patients. Details are shown in Table II.

Response to treatment. The response to the treatment was defined according to the NCI criteria: CR, complete remission; $\mathrm{PR}$, partial remission; $\mathrm{SD}$, stable disease and $\mathrm{PD}$, progressive disease (23).

Comparison of the percentage of apoptotic cells in patients who responded and who did not respond to treatment (according to the NCI criteria). We found no significant differences between the post-treatment percentage of apoptotic cells in patients who responded and who did not respond to treatment, though we noted that in the first group $(\mathrm{CR}+\mathrm{PR}$ patients) apoptosis increased after treatment (similar to earlystage patients), while in the latter group (SD+PD patients) it decreased (similar to advanced-stage patients) compared to pre-treatment apoptosis. However, the pre-treatment percentage of apoptotic $\left(\Delta \Psi_{\mathrm{m}}^{\text {low }} / \mathrm{Gly}-\mathrm{A}\right.$ and $\left.\mathrm{Ann}-\mathrm{V}^{+} / \mathrm{PI}^{-}\right)$cells was significantly higher in patients who did not respond compared to those who responded.

The pre-treatment percentage of apoptotic cells in patients who did not survive due to the progression of B-CLL compared to those who survived
CMXRos. The ex vivo percentage of apoptotic $\left(\Delta \Psi_{\mathrm{m}}^{\text {low }} / \mathrm{Gly}-\mathrm{A}^{-}\right)$ cells before treatment in B-CLL patients who had a short survival due to the progression of the disease (mean $6.0 \pm 6.6 \%$ and median $3.7 \%)$ was significantly higher $(\mathrm{p}<0.05)$ than the

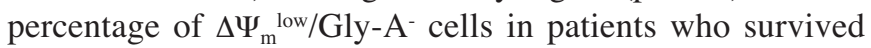
(mean $2.7 \pm 2.0 \%$ and median $2.2 \%$ ).

FDA. The ex vivo percentage of apoptotic (FDA-/ $\left.\mathrm{PI}^{-}\right)$cells before treatment in B-CLL patients who had a short survival due to the progression of the disease (mean $2.9 \pm 1.5 \%$ and median $2.7 \%)$ was significantly higher $(\mathrm{p}<0.01)$ than the percentage of $\mathrm{FDA}^{-} / \mathrm{PI}$ - cells in patients who survived (mean $1.6 \pm 1.3 \%$ and median $1.4 \%$ ).

Annexin $V$. The ex vivo percentage of apoptotic $\left(\mathrm{Ann}-\mathrm{V}^{+} / \mathrm{PI}\right)$ cells before treatment in B-CLL patients who did not survive due to the progression of the disease (mean $1.6 \pm 1.6 \%$ and median $1.1 \%$ ) was comparable to the percentage of FDA-PI cells in patients who survived (mean $1.4 \pm 1.0 \%$ and median $1.2 \%, \mathrm{NS})$.

Percentage of apoptotic cells in patients with advanced $B$ $C L L$ (APO). From the group of patients who had a short survival due to the progression of the disease, we separated an additional subgroup of patients. They were B-CLL patients whose pre-treatment percentage of apoptotic cells was high, and which decreased after treatment (therefore the group was 
Table II. The percentage of apoptotic cells during purine analogue administration evaluated by CMXRos staining $\left(\Delta \Psi_{\mathrm{m}}{ }^{\text {low }} / \mathrm{Gly}-\mathrm{A}\right.$ cells) and Annexin V technique (Ann- $\mathrm{V}^{+} / \mathrm{PI}^{-}$cells): before treatment (0), as well as 3 and $24 \mathrm{~h}$ after the first dose of drug administration (during the initial cycle of therapy) in 0-II Rai stage patients (A) and in III-IV Rai stage patients (B); ${ }^{\mathrm{a}, \mathrm{b}, \mathrm{c}, \mathrm{d}} \mathrm{p}<0.05$.

A, 0-II Rai stage patients during purine analogue therapy

\begin{tabular}{|c|c|c|c|c|}
\hline \multirow[b]{2}{*}{ Hours } & \multicolumn{2}{|c|}{$\Delta \Psi_{\mathrm{m}}^{\text {low/Gly-A- apoptotic cells }(\%)}$} & \multicolumn{2}{|c|}{ Ann-V+/PI- apoptotic cells (\%) } \\
\hline & $\begin{array}{l}\text { Mean } \pm \text { SD } \\
(\min .-\max .)\end{array}$ & Median & $\begin{array}{l}\text { Mean } \pm \mathrm{SD} \\
(\min .-\max .)\end{array}$ & Median \\
\hline 0 & $3.7 \pm 3.2$ & $\begin{array}{c}2.8^{\mathrm{a}, \mathrm{b}} \\
(0.4-11.9)\end{array}$ & $1.5 \pm 1.4$ & $\begin{array}{c}1.1^{\mathrm{c}, \mathrm{d}} \\
(0.1-5.0)\end{array}$ \\
\hline 3 & $5.4 \pm 4.2$ & $\begin{array}{c}3.9^{\mathrm{a}} \\
(1.0-13.8)\end{array}$ & $2.6 \pm 2.4$ & $\begin{array}{c}1.5^{\mathrm{c}} \\
(0.4-7.9)\end{array}$ \\
\hline 24 & $6.0 \pm 5.1$ & $\begin{array}{c}4.5^{\mathrm{b}} \\
(0.8-18.2)\end{array}$ & $2.5 \pm 1.5$ & $\begin{array}{c}2.1^{\mathrm{d}} \\
(0.1-5.1)\end{array}$ \\
\hline
\end{tabular}

B, III-IV Rai stage patients during purine analogue therapy

\begin{tabular}{|c|c|c|c|c|}
\hline \multirow[b]{2}{*}{ Hours } & \multicolumn{2}{|c|}{$\Delta \Psi_{\mathrm{m}}^{\text {low }} / \mathrm{Gly}-\mathrm{A}^{-}$apoptotic cells $(\%)$} & \multicolumn{2}{|c|}{ Ann-V+/PI- apoptotic cells $(\%)$} \\
\hline & $\begin{array}{l}\text { Mean } \pm \text { SD } \\
(\min .-\max .)\end{array}$ & Median & $\begin{array}{l}\text { Mean } \pm \text { SD } \\
\text { (min.-max.) }\end{array}$ & Median \\
\hline 0 & $7.0 \pm 7.3$ & $\begin{array}{c}4.5^{\mathrm{a}} \\
(0.7-26.6)\end{array}$ & $2.3 \pm 1.6$ & $\begin{array}{c}2.2^{\mathrm{b}, \mathrm{c}} \\
(0.4-5.6)\end{array}$ \\
\hline 3 & $3.1 \pm 2.8$ & $\begin{array}{c}2.4^{\mathrm{a}} \\
(1.0-11.4)\end{array}$ & $1.0 \pm 0.5$ & $\begin{array}{c}0.8^{\mathrm{b}} \\
(0.2-1.9)\end{array}$ \\
\hline 24 & $5.0 \pm 7.9$ & $\begin{array}{c}2.6 \\
(0.9-30.6)\end{array}$ & $1.5 \pm 1.3$ & $\begin{array}{c}1.2^{\mathrm{c}} \\
(0.3-4.7)\end{array}$ \\
\hline
\end{tabular}

termed APO). All of the patients included in this group had either SD or PD according to the NCI criteria.

We compared the percentage of apoptotic cells in APO patients with all of the examined B-CLL patients, as well as with those who achieved CR or PR (Fig. 3).

CMXRos. The ex vivo percentage of apoptotic $\left(\Delta \Psi_{\mathrm{m}}{ }^{\text {low }} /\right.$ Gly-A-) cells before treatment in APO patients (mean $12.3 \pm 9.6 \%$ and median $11.6 \%$ ) was significantly higher $(\mathrm{p}<0.01)$ than that of $\Delta \Psi_{\mathrm{m}}{ }^{\text {low }} / \mathrm{Gly}-\mathrm{A}^{-}$cells in all of the examined B-CLL (mean 2.8 $\pm 2.3 \%$ and median 2.4\%), and CR+PR patients (mean 2.9 $2.4 \%$, median 1.8\%), (Fig. 3).

In patients who achieved $\mathrm{CR}$ or $\mathrm{PR}(\mathrm{CR}+\mathrm{PR})$ the ex vivo percentage of apoptotic $\left(\Delta \Psi_{\mathrm{m}}^{\text {low/Gly-A}}\right)$ cells after chemotherapy (mean $6.4 \pm 6.7 \%$ and median $3.9 \%$ ) was significantly higher $(\mathrm{p}<0.05)$ than that of apoptotic cells before treatment, whereas in APO patients the post-treatment percentage of ex vivo apoptotic cells (mean $6.9 \pm 8.5 \%$ and median $2.6 \%$ ) was significantly lower $(\mathrm{p}<0.05)$ than that of apoptotic cells before cytostatic therapy (Fig. 4).

FDA. The ex vivo percentage of apoptotic (FDA-/PI') cells

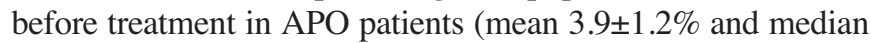
$4.2 \%)$ was significantly higher $(\mathrm{p}<0.01)$ than that of $\mathrm{FDA}^{-} / \mathrm{PI}^{-}$ cells in all of the examined B-CLL (mean $1.7 \pm 1.3 \%$ and median $1.4 \%$ ) and $\mathrm{CR}+\mathrm{PR}$ patients (mean $2.1 \pm 2.0 \%$ and median $1.9 \%$ ).

Annexin $V$. The ex vivo percentage of apoptotic (Ann- $\left.\mathrm{V}^{+} / \mathrm{PI}\right)$ cells before treatment in APO patients (mean $3.7 \pm 1.4 \%$ and median $3.2 \%)$ was significantly higher $(\mathrm{p}<0.01)$ than that of the Ann- $\mathrm{V}^{+} / \mathrm{PI}^{-}$cells in all of the examined B-CLL (mean $1.4 \pm 1.1 \%$ and median $1.1 \%$ ), and $\mathrm{CR}+\mathrm{PR}$ patients (mean $1.4 \pm 0.8 \%$ and median $1.2 \%$ ), (Fig. 3 ).

In $\mathrm{CR}+\mathrm{PR}$ patients the ex vivo percentage of apoptotic (Ann- $\mathrm{V}^{+} / \mathrm{PI}$ ) cells after the cytostatic administration (mean $3.4 \pm 4.8 \%$ and median $1.5 \%)$ was significantly higher $(\mathrm{p}<0.05)$ than that of apoptotic cells before treatment, whereas in the APO patients the percentage of ex vivo apoptotic cells after chemotherapy (mean $1.6 \pm 1.2 \%$ and median $1.3 \%$ ) was significantly lower $(\mathrm{p}<0.05)$ than the pre-treatment percentage of apoptotic cells (Fig. 4).

Correlations between the results achieved by the different methods of apoptosis evaluation. We found significant positive correlations between the results achieved by the three different methods of apoptosis evaluation in most time points (data not shown). The differences between the results at some points may be caused by the different time windows 
A

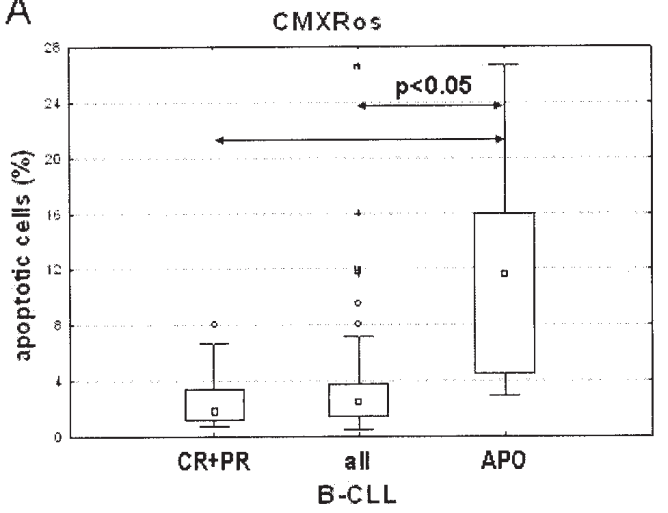

B

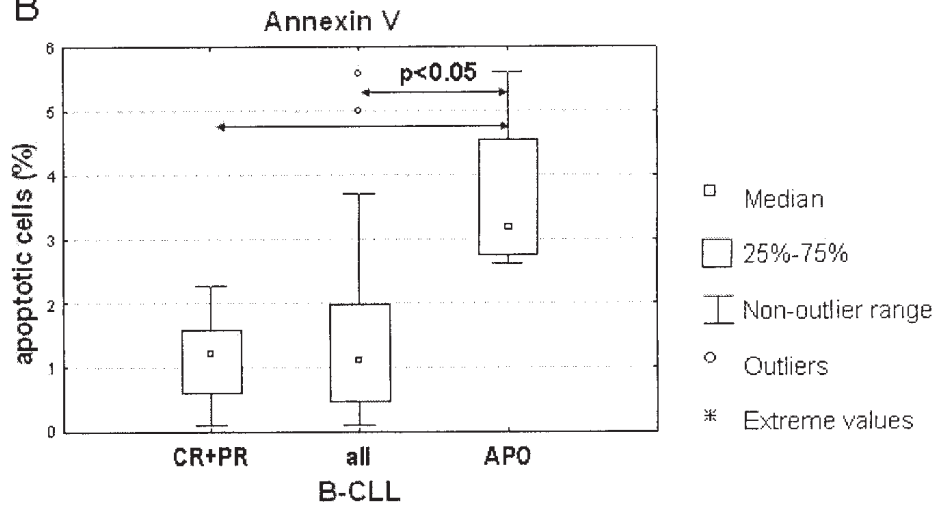

Figure 3. The ex vivo percentage of apoptotic cells evaluated by CMXRos (A) and Annexin V (B) before treatment in three groups of patients: those who achieved CR or PR, in all of the examined B-CLL patients and in those with advanced disease (APO). The APO group was separated from the group of patients who had a short survival due to the progression of the disease. Those were B-CLL patients whose pre-treatment percentage of apoptotic cells was significantly higher $(\mathrm{p}<0.01)$ than that of all of the examined patients, and in patients who achieved $C R$ or $P R(C R+P R$ patients $)$, decreasing after treatment. All of the patients included in the APO group had either SD or PD according to the NCI criteria.

A

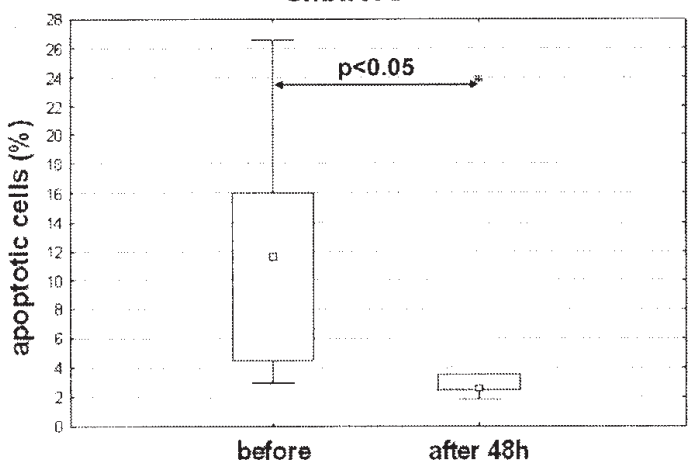

APO

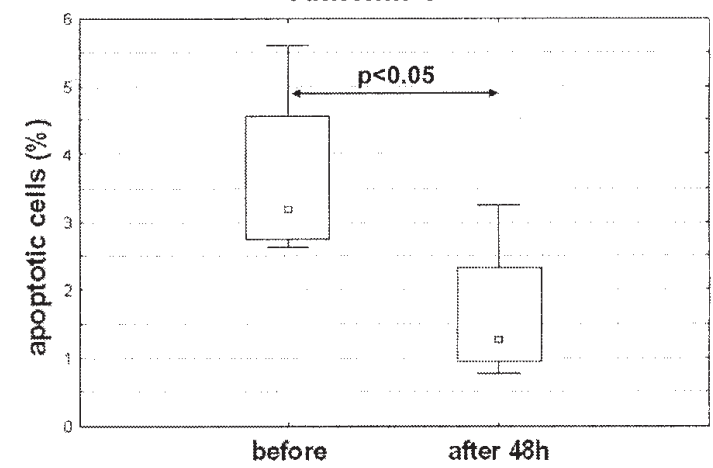

C

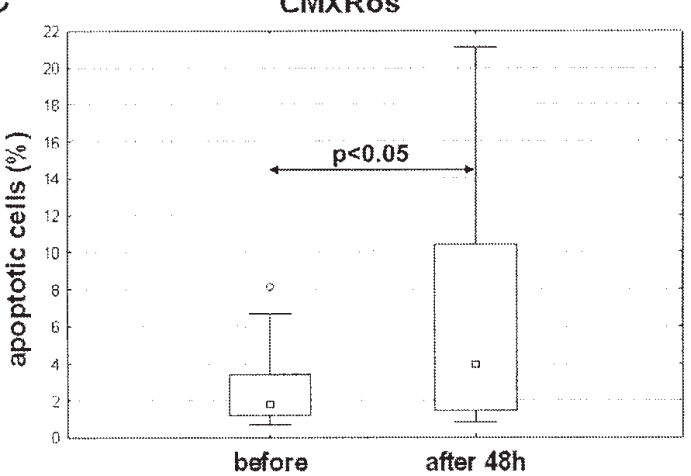

CR+PR

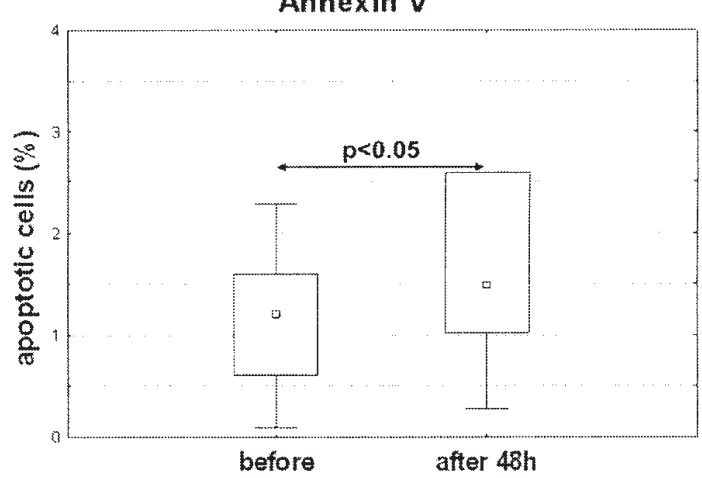

B

D

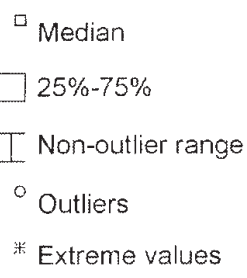

Figure 4. A comparison of the ex vivo percentage of apoptotic cells evaluated by CMXRos (A and C) and Annexin V (B and D) before treatment and $48 \mathrm{~h}$ after the first dose of drug administration in the patients with advanced disease (APO patients, A-B) and in the patients who achieved CR or PR (C-D). In APO patients the post-treatment percentage of ex vivo apoptotic cells was significantly lower $(\mathrm{p}<0.05)$ than the percentage of apoptotic cells before anti-cancer therapy, whereas in $\mathrm{CR}+\mathrm{PR}$ patients the percentage of ex vivo apoptotic cells after chemotherapy was significantly higher (p<0.05) than before the treatment.

of the methods and by the fact that they evaluate different phenomena of the apoptotic pathway.

We noted a higher percentage of apoptosis evaluated by CMXRos staining compared to the FDA and Annexin-V technique, in healthy subjects and B-CLL patients (Figs. 2-4).
Cell culture. We found that the in vitro percentage of apoptotic cells in a 24-h culture of leukaemic cells (median 19.1\%) in the complete medium was significantly higher $(p<0.05)$ than that of the apoptotic cells in the culture of healthy individual cells (median $8.1 \%$ ). Similarly, after $48 \mathrm{~h}$ the in vitro 
percentage of apoptotic cells in the leukaemic cell culture (median 30.3\%) in the complete medium was significantly higher $(\mathrm{p}<0.05)$ than that of the apoptotic cells in the culture of healthy individual cells (median 19.5\%).

\section{Discussion}

One of the most important findings of the studies on cancer biology has been the discovery that apoptosis plays an essential role in the development of the disease and in the treatment response. Many anti-cancer therapies, including chemotherapy and ionising radiation, act through apoptosis induction in target cells. It is known that deregulated apoptosis plays a role in the pathogenesis of B-cell chronic lymphocytic leukaemia. We hypothesised that the evaluation of ex vivo apoptosis might provide new important information concerning the biology and prognosis of B-CLL.

In our study, we used three methods of early apoptosis evaluation, based on the assessment of three different events in the apoptotic pathway, with CMXRos being the basic technique. CMXRos is a fluorochrome that can be used to detect disruptions in the mitochondrial membrane potential $\left(\Delta \Psi_{\mathrm{m}}\right)$, one of the earliest events in the apoptotic pathway $(17,19,20)$. The collapse of $\Delta \Psi_{\mathrm{m}}$ is a marker of early apoptosis, preceding other hallmarks of cell death, such as DNA fragmentation or phosphatidylserine externalisation (detected by Annexin V) (24-26). This method has allowed us to evaluate the very early stages of apoptosis ex vivo, when apoptotic cells are still present in peripheral blood. The percentage of the cells with a disrupted $\Delta \Psi_{\mathrm{m}}$ measured by CMXRos was generally higher than that of apoptotic cells evaluated by FDA or Annexin V in all of the studies performed. It appears likely that early apoptotic cells (cells with a disrupted $\Delta \Psi_{\mathrm{m}}$ in CMXRos staining) circulate in peripheral blood, while cells representing later events in the apoptotic pathway (Annexin V-positive cells) are phagocitised by endothelial cells, and therefore are impossible to detect ex vivo. These results suggest that the CMXRos technique is a sensitive method in assessing the number of apoptotic cells ex vivo in peripheral blood.

As expected, the spontaneous apoptosis in B-CLL patients before treatment was significantly lower compared to the healthy controls. Low ex vivo spontaneous apoptosis in patient peripheral blood confirmed the defective apoptosis as one of the mechanisms of leukaemic lymphocyte accumulation in B-CLL. A new finding of our study was that ex vivo spontaneous apoptosis was higher in advanced- (III-IV acc. Rai) than in early-stage (I-II acc. Rai) patients. Moreover, in III-IV Rai stage patients the percentage of ex vivo apoptotic cells after chemotherapy was lower than before therapy, whereas in I-II Rai stage patients the percentage of ex vivo apoptotic cells after chemotherapy was higher than before the treatment. It is known that the advanced stage is an unfavourable prognostic factor in B-CLL, frequently associated with resistance to chemotherapy $(27,28)$. However, the high percentage of apoptotic cells in untreated advanced-stage patients and a positive correlation between the percentage of apoptotic cells and B-CLL stage are original and notable observations. To our knowledge this is the first study showing such results. One can speculate that processes other than the accumulation of undying cells could also be responsible for a high lymphocyte count in the advanced stages of B-CLL. The recent results of Messmer et al (10) suggest that proliferation may be an important factor contributing to tumour mass growth in B-CLL. This finding has suggested that the B-CLL clone proliferates at appreciable rates and cells produced in the bone marrow, lymph nodes or spleen may be slowly released into other compartments. Similarly, we found that advanced-stage (III-IV acc. Rai) patients showed higher proliferation rates (measured by the incorporation of $\left[{ }^{3} \mathrm{H}\right]$ thymidine) than early-stage ones (0-II acc. Rai) (preliminary data not shown). The higher percentage of apoptotic cells in advanced-stage patients showing high proliferation rates may be associated with activation-induced cell death (AICD). Taken together, with the higher ex vivo spontaneous apoptosis in advanced- (III-IV acc. Rai) versus early-stage (I-II acc. Rai) patients, our findings are in line with the observations of Messmer et al $(10,29)$, who have shown that an active and progressive B-CLL correlates with higher birth rates of B-CLL cells, which may be connected with high cell death rates in patients with high turnover rates and stable WBC counts. Thus a stable WBC count need not reflect disease activity. These observations may explain the heterogeneity in the clinical course and emphasise the role of prognostic factors in B-CLL, crucial for developing risk-adapted therapeutic strategies.

A theory suggesting a three-step model of the natural history of indolent lymphomas, including B-CLL, exists. The first step is an unknown genetic abnormality (or abnormalities) responsible for the clone of the transformed cells that appear. Malignant cells then start to accumulate, probably due to deregulated apoptosis, and their interactions with the microenvironment contribute to apoptosis deregulation (the second step). Over time, with the appearance of new, more dangerous genetic abnormalities, leukaemic cells begin their autonomous proliferation (third step). Prolymphocytoid or Richter's transformations of B-CLL represent examples of the disease progression from the second to the third step (30). Thus in advanced-stage B-CLL patients, the clone of malignant cells, previously arrested in $\mathrm{G}_{0} / \mathrm{G}_{1}$, may evolve into an actively proliferating population. It is likely that these autonomously proliferating cells show a greater ability to enter spontaneous apoptosis, while being more resistant to drug-induced apoptosis. It may explain the results of our studies, which are the high percentage of apoptotic cells in untreated III-IV Rai stage B-CLL patients and a direct correlation between the percentage of apoptotic cells and the disease stage.

Investigations have shown that cell proliferation and death rates differ considerably among B-CLL patients and the level of cell turnover is important for the natural history of disease progression in an individual patient, which can have significant clinical implications $(10,16)$. These observations may contribute to understanding the biology of B-CLL and explain its heterogeneity as well as contrasts between the results achieved by various researchers. Oliveira et al (31) showed an inverse correlation between the percentage of Annexin V-positive cells and the Rai stage in B-CLL. They concluded that the progression of B-CLL is accompanied by a loss of the capacity to enter apoptosis in vitro. However, they estimated the spontaneous apoptosis of lymphocytes after 
$48 \mathrm{~h}$ of culture, so these findings are incomparable with our ex vivo results. Ricciardi et al (32) found that cultured B-CLL cells from patients with progressive disease were characterised by a more quiescent status (lower RNA content of $\mathrm{G}_{0} / \mathrm{G}_{1}$ ) and a much lower susceptibility to apoptosis when compared with stable disease patients. However, in fresh B-CLL samples, no significant differences in the mean values of apoptosis between patients with progressive and stable disease were observed.

On analysing the results of our ex vivo studies, we observed no significant correlations between the percentage of apoptotic cells and such prognostic factors as the lactate dehydrogenase (LDH) or $\beta_{2}$-microglobulin levels, as well as CD38 or ZAP-70 expression. It is likely that there is no direct link between these risk factors and apoptosis regulation in B-CLL cells. Messmer et al (10) also did not identify a significant correlation between the LDH level, CD38 and ZAP-70 expression or Ig VH gene mutation status and birth or death rates of B-CLL cells. They have suggested that birth or death rates are real-time markers of the B-CLL cell kinetic activities, while the former markers presage the eventual outcome for an individual patient.

As mentioned in Results, from the group of patients who had a short survival due to the progression of the disease, we have separated the subgroup of patients (termed APO), whose pre-treatment percentage of apoptotic cells was 3 times higher than in all of the examined patients, but decreased after treatment. All of the patients included in this group had either SD or PD according to the NCI criteria. However, we found some differences between them. For instance, P41 had been in the II Rai stage when included in this study, and 12 months later her condition transformed into Richter's syndrome and she had a short survival. In Richter's syndrome multiple genetic defects have been described, which may cause leukaemic cells to proliferate. Thus, the highly spontaneous apoptosis in P41 may have reflected a high cell turnover with high birth and death rates. The case of this patient emphasises the significance of prognostic factors in B-CLL, as the clinical staging systems do not allow for the prediction of any further clinical course of the disease in an individual patient when diagnosed in the early stage. In another patient from this group (P14, IV stage acc. Rai), during the first cycle of chemotherapy the post-treatment WBC count was higher than the pre-treatment $\mathrm{WBC}$ one and similarly, the posttreatment peripheral lymphocyte count was higher than the pre-treatment lymphocyte one, while, similar to other APO patients, post-treatment apoptosis was lower than the pretreatment apoptosis. Could the high pre-treatment spontaneous apoptosis be considered as an unfavourable prognostic factor in patients with stable or increasing WBC counts? This issue needs further investigation but our results seem to support such a possibility. It appears likely that a standard evaluation of the percentage of apoptotic cells in all of the untreated B-CLL patients, using the method enabling the ex vivo detection of early apoptotic cells, may help to predict the clinical outcome for an individual patient.

\section{References}

1. Debatin KM, Stahnke K and Fulda S: Apoptosis in haematological disorders. Semin Cancer Biol 13: 149-158, 2003.
2. Reed JC: Molecular biology of chronic lymphocytic leukemia. Semin Oncol 25: 11-18, 1998.

3. Caligaris-Cappio F and Hamblin TJ: B-cell chronic lymphocytic leukemia: a bird of a different feather. J Clin Oncol 17: 399-408, 1999.

4. Danilov AV, Danilova OV, Klein AK and Huber BT: Molecular pathogenesis of chronic lymphocytic leukemia. Curr Mol Med 6: 665-675, 2006.

5. Dighiero G: CLL Biology and Prognosis. Hematology (Am Soc Hematol Educ Program) pp278-284, 2005.

6. Reed JC and Kitada S: Apoptosis Disregulation in Chronic Lymphocytic Leukemia. In: Chronic Lymphoid Leukemias. Cheson BD (ed). Marcel Dekker, Inc., New York pp111-126, 2001.

7. Caligaris-Cappio F: New insights into the biology of B-chronic lymphocytic leukemia. Hematology (Am Soc Hematol Educ Program) pp249-254, 1999.

8. Haiat S, Billard C, Quiney C, Ajchenbaum-Cymbalista F and Kolb JP: Role of BAFF and APRIL in human B-cell chronic lymphocytic leukaemia. Immunology 118: 281-292, 2006.

9. Decker T, Hipp S, Ringshausen I, Bogner C, Oelsner M, Schneller F and Peschel C: Rapamycin-induced G1 arrest in cycling B-CLL cells is associated with reduced expression of cyclin D3, cyclin E, cyclin A and survivin. Blood 101: 278-285, 2003.

10. Messmer BT, Messmer D, Allen SL, Kolitz JE, Kudalkar P, Cesar D, Murphy EJ, Koduru P, Ferrarini M, Zupo S, Cutrona G, Damle RN, Wasil T, Rai KR, Hellerstein MK and Chiorazzi N: In vivo measurements document the dynamic cellular kinetics of chronic lymphocytic leukemia B cells. J Clin Invest 115: 755-764, 2005.

11. Crespo M, Bosch F, Villamor N, Bellosillo B, Colomer D, Rozman M, Marce S, Lopez-Guillermo A, Campo E and Montserrat E: ZAP-70 expression as a surrogate for immunoglobulin-variable-region mutations in chronic lymphocytic leukemia. N Engl J Med 348: 1764-1775, 2003.

12. Schroers R, Griesinger F, Trumper L, Haase D, Kulle B, Klein-Hitpass L, Sellmann L, Duhrsen U and Durig J: Combined analysis of ZAP-70 and CD38 expression as a predictor of disease progression in B-cell chronic lymphocytic leukemia. Leukemia 19: 750-758, 2005.

13. Hus I, Podhorecka M, Bojarska-Junak A, Rolinski J, Schmitt M, Sieklucka M, Wasik-Szczepanek E and Dmoszynska A: The clinical significance of ZAP-70 and CD38 expression in B-cell chronic lymphocytic leukaemia. Ann Oncol 17: 683-690, 2006.

14. Bojarska-Junak A, Giannopoulos K, Kowal M, Dmoszynska A and Rolinski J: Comparison of methods for determining zetachain associated protein - 70 (ZAP-70) expression in patients with B-cell chronic lymphocytic leukemia (B-CLL). Cytometry B Clin Cytom 70B: 293-301, 2006.

15. Bojarska-Junak A, Rolinski J and Kawiak J: Modification of immunocytochemical ZAP-70 assay for potential clinical application in B-cell chronic lymphocytic leukemia. Folia Histochem Cytobiol 43: 19-23, 2005.

16. Chiorazzi $\mathrm{N}$ and Ferrarini M: Evolving view of the in vivo kinetics of chronic lymphocytic leukemia B cells. Hematology (Am Soc Hematol Educ Program) pp273-278, 2006.

17. Macho A, Decaudin D, Castedo M, Hirsch T, Susin SA, Zamzami N and Kroemer G: Chloromethyl-X-rosamine - a fluorochrome for the determination of the mitochondrial transmembrane potential. Cytometry 31: 75, 1998.

18. Pendergrass W, Wolf $\mathrm{N}$ and Poot M: Efficacy of MitoTracker Green $^{\mathrm{TM}}$ and CMXRosamine to measure changes in mitochondrial membrane potentials in living cells and tissues. Cytometry 61A: 162-169, 2004.

19. Poot M and Pierce RC: Detection of apoptosis and changes in mitochondrial membrane potential with chloromethyl-Xrosamine. Cytometry 36: 359-360, 1999.

20. Pozarowski P, Huang X, Halicka DH, Lee B, Johnson G and Darzynkiewicz Z: Interactions of fluorochrome-labeled caspase inhibitors with apoptotic cells: a caution in data interpretation. Cytometry A 55: 50-60, 2003.

21. Bartkowiak D, Hogner S, Baust H, Nothdurft W and Röttinger EM: Comparative analysis of apoptosis in HL60 detected by Annexin-V and fluorescein-diacetate. Cytometry 37: 191-196, 1999.

22. Merchant SH, Gonchoroff NJ and Hutchison RE: Apoptotic index by Annexin V flow cytometry: Adjunct to morphologic and cytogenetic diagnosis of myelodysplastic syndromes. Cytometry 46: 28-32, 2001 
23. Cheson BD, Bennett JM, Grever M, Kay N, Keating MJ, O'Brien S and Rai KR: National Cancer Institute-sponsored Working Group guidelines for chronic lymphocytic leukemia: revised guidelines for diagnosis and treatment. Blood 87: 4990-4997, 1996.

24. Rasola A and Geuna M: A flow cytometry assay simultaneously detects independent apoptotic parameters. Cytometry 45: 151-157, 2001.

25. Stahnke K, Fulda S, Friesen C, Strauss G and Debatin KM: Activation of apoptosis pathways in peripheral blood lymphocytes by in vivo chemotherapy. Blood 98: 3066-3073, 2001.

26. Vermes I, Haanen C and Reutelingsperger C: Flow cytometry of apoptotic cell death. J Immunol Methods 243: 167-190, 2000.

27. Byrd JC: Management of patients with fludarabine-refractory CLL. Hematology (Am Soc Hematol Educ Program) pp175$183,2004$.

28. Gribben JG: Salvage therapy for CLL and the role of stem cell transplantation. Hematology (Am Soc Hematol Educ Program) pp292-298, 2005.
29. Chiorazzi N, Messmer B, Damle RN, Allen SL, Rai KR and Ferrarini M: Unraveling the biology of chronic lymphocytic leukemia. Hematology (Am Soc Hematol Educ Program) pp153-160, 2003.

30. Caligaris-Cappio F, Cignetti A, Granziero L and Ghia P: Chronic lymphocytic leukaemia: a model for investigating potential new targets for the therapy of indolent lymphomas. Best Pract Res Clin Haematol 15: 563-575, 2002.

31. Oliveira GB, Pereira FG, Metze K and Lorand-Metze I: Spontaneous apoptosis in chronic lymphocytic leukemia and its relationship to clinical and cell kinetic parameters. Cytometry 46: 329-335, 2001.

32. Ricciardi MR, Petrucci MT, Gregorj C, Ariola C, Lemoli RM, Fogli M, Mauro FR, Cerretti R, FoA R, Mandelli F and Tafuri A: Reduced susceptibility to apoptosis correlates with kinetic quiescence in disease progression of chronic lymphocytic leukaemia. Br J Haematol 113: 391-399, 2001. 